\title{
THE DETECTION OF HEAVY PETROLEUM IN PAINTS AND VEGETABLE OILS.
}

\author{
By W. B. POLLARD. \\ (Read at the Meeting, May 1, 1912.)
}

OwING to the present extensive use of turpentine substitutes, petroleum is now frequently found in mixed paints. Whatever views are held with regard to the value of light petroleum as a turpentine substitute, there is no doubt that heavy petroleum should never be present in paints. As the drying property of such paints can never be satisfactory, it is important to be able to detect the presence of this substance. Light petroleum can be readily separated by steam distillation; and by the action of sulphuric acid, this may further be separated from any turpentine present. Heavy petroleum is not so readily detected, though it can be found by the method described 
in Allen's "Commercial Organic Analysis." This method, though satisfactory for quantitative work, requires far too much time and manipulation to be of much use as a qualitative test for petroleum. Experiments were therefore made to find in what way it could be modified, in order to give rapid results. It was noticed that when linseed oil is poured into an excess of molten caustic soda and stirred with an iron rod, complete saponification takes place in a few seconds; the soap thus obtained, after cooling, can be extracted with petroleum ether without any passing into the solution and without any emulsion being formed. The petroleum ether extract, which can easily be filtered, will then contain the unsaponifiable oil. Should heavy petroleum be present, it will often betray its presence by the strong fluorescence imparted to the solution.

On evaporating the petroleum ether, petroleum is left behind, and a further examination can be made. In the case of normal linseed oils, a small residue of unsaponifiable oil, rarely exceeding 2 per cent., is always left after extraction; it was noticed that this unsaponifiable oil could further be removed by boiling with a good excess of strong nitric acid, only the minutest trace, if any, remaining after this treatment. Should, however, heavy petroleum be present in the linseed oil, this will reveal itself by the large amount of unsaponifiable matter, and will remain unattacked by the treatment with nitric acid. It was found that as little as 0.5 per cent. of heavy petroleum, when present in linseed oil, could be detected by this means. It is most conspicuous when the nitric acid is warmed, as the oil tends to creep up the side of the tube. Light petroleum or turpentine is not detected in this way, as they volatilise at the temperature at which the saponification takes place; as previously mentioned, they would be detected by steam distillation.

The actual method of conducting the test is as follows:-About 10 grms. of caustic soda are placed in a nickel crucible of 60 to 100 c.c. capacity, and fused over a Bunsen burner. When all the soda has just melted, the crucible is removed from the flame, and about 5 c.c. of the oil or paint quickly poured in. The contents are well stirred with an iron rod, and the crucible allowed to stand in a little water to cool. When cool, about 50 c.c. of petroleum ether are poured into the crucible, and the contents well stirred with the iron rod. By this method the soap forms a powder which settles at the bottom of the crucible, and an emulsion is never produced.

The petroleum ether solution is decanted through a filter-paper and received in a test-tube. It is then boiled off, the vapour being conducted away through a glass tube fixed by means of a cork in the mouth of the test-tube. The residue can now be further examined; this is done by boiling with about 3 c.c. of nitric acid, when any residue beyond a minute trace will be petroleum. Should a paint be found by this method to contain petroleum, it must be absolutely condemned, as its drying properties can never be satisfactory.

It is sometimes stated that resin oil is added to paints. Should this occur, it would be detected by the large amount of unsaponifiable matter, but would be distinguished from petroleum by the fact that it is oxidised by boiling with nitric acid. It might be thought that the Zeiss butyro-refractometer reading of the unsaponifiable matter would afford an indication of the presence of petroleum ; this, 
however, is not the case, as both the heavy petroleum and the unsaponifiable matter normally present in linseed oil give readings which are outside the scale of the instrument.

This method may be used in examining other kinds of saponifiable oils for petroleum adulteration. A small quantity of unsaponifiable oil is left in nearly every case, but on boiling this with an excess of nitric acid, it is invariably destroyed.

The method can also be applied in the examination of stearine candles, which, when they contain paraffin, soften at a temperature considerably below their meltingpoint.

No claim is made that the method is quantitative, but it affords a ready means for the detection of heavy petroleums when mixed with saponifiable oil, and should not take more than about ten minutes to perform.

Survey Department laboratories, Cairo.

\section{Discussion.}

Mr. Raymond Ross said that a determination of the factor $\frac{\mu-1}{d}$ in the residue would nearly always indicate whether it consisted of petroleum, and would in many cases show to what class of petroleum it belonged. In the case of nearly all petroleum oils this value was quite definite, varying from 0.557 to 0.543 , while the figure for fatty oils was much different.

The President agreed that it seemed improbable that so little as 1 per cent. of mineral oil would be used as an actual adulterant, unless it were added to mask some other addition. Small quantities of mineral oil were, however, sometimes met with in fatty oils obtained by extraction with a solvent, owing to incomplete evaporation of the solvent. This had the effect of considerably lowering the flash-point of the oil, and also, to some extent, the viscosity.

Mr. E. Richards BoLton said that it was now unusual to find any trace of solvent in extracted oil, because in most modern extraction plants arrangements were made for blowing steam through the oil in order to remove the last traces of solvent, and manufacturers, for reasons of economy, were usually careful to carry out this operation as thoroughly as possible.

The President said that, although it might occur but rarely, it certainly was occasionally the case that the manufacturer did not succeed in removing the last traces of volatile solvent. A sample of extracted rape oil that he had lately examined lost 0.36 per cent. when 1 grm. was heated for an hour in the water-oven, and its flash-point (close test) was only $286^{\circ} \mathrm{F}$., whereas the flash-point of rape oil obtained by pressure from the seed would not be below $400^{\circ} \mathrm{F}$.

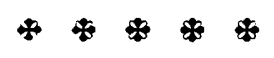

